\title{
CONSECUENCIAS DEL INCUMPLIMIENTO DE LOS CONTRATOS A CAUSA DEL COVID-19 EN EL DERECHO ARGENTINO
}

\author{
Sebastián Picasso \\ Universidad de Buenos Aires, Buenos Aires, Argentina \\ Recibido: 7/8/2020 - Aprobado: 14/8/2020 \\ doi: https://doi.org/10.26439/iusetpraxis2020.n50-51.5041
}

\begin{abstract}
RESUMEN. El problema que se plantea en el presente texto versa sobre los efectos que produce el incumplimiento en los contratos suscritos en Argentina como consecuencia de la pandemia del coronavirus. Para comenzar, debido a dicha pandemia, los gobiernos de varios países del mundo han decidido adoptar distintas medidas de emergencia, entre las cuales se destaca el aislamiento social obligatorio, por lo que se ha generado una abrupta caída de las diversas actividades económicas y, por lo tanto, la imposibilidad de cumplir muchos contratos en curso. Frente a ello, cabría preguntarse cuáles son los remedios o las salidas que ofrece el derecho positivo para resolver tal problema.
\end{abstract}

PALABRAS CLAVE: pandemia / aislamiento social obligatorio / contrato / obligación / caso fortuito / incumplimiento / imposibilidad / renegociación

\section{CONSEQUENCES OF BREACH OF CONTRACT DUE TO COVID-19 UNDER THE ARGENTINE LAW}

ABSTRACT. This paper addresses the problem caused by the effects of breach of contracts entered into in Argentina as a result of the coronavirus pandemic. To begin with, due to the coronavirus pandemic, the governments of several countries worldwide have decided to take different emergency measures, among which compulsory social distancing stands out. Said situation has generated an abrupt fall in the various economic activities and, therefore, the impossibility to fulfill many ongoing contracts. In view of this, one might ask oneself what remedies or solutions are offered by positive law to solve this problem.

KEYWORDS: pandemic / mandatory social distancing / contract / obligation / act of God / breach / impossibility / renegotiation 
En el derecho argentino hay una serie de institutos que, según la doctrina, pueden aplicarse ante el incremento de casos de incumplimientos contractuales como consecuencia de los efectos de la pandemia del coronavirus, tales como el aislamiento social obligatorio, la cuarentena y el impedimento de entrada y salida del país, a saber: i) la invocación de un caso fortuito, ii) la aplicación de la teoría de la imprevisión, iii) la frustración del fin del contrato y iv) la renegociación contractual. Aunque haremos hincapié en la primera de esas instituciones, dedicaremos unas breves consideraciones finales a la cuestión de la renegociación de los contratos.

En el sistema del Código Civil y Comercial argentino, el deudor se obliga hasta el límite de la imposibilidad. La idea es que, en tanto haya incumplimiento, hay responsabilidad del deudor, salvo que este pruebe que dicho incumplimiento se ha debido a un caso fortuito que produjo una imposibilidad de cumplimiento sobrevenida, objetiva, absoluta, definitiva y no imputable al obligado. Entonces, hay cumplimiento forzado, y eventualmente también responsabilidad del deudor, hasta el límite de un caso fortuito que causa esa imposibilidad.

La imposibilidad se encuentra expresamente regulada por dos normas del Código Civil y Comercial argentino: el artículo 955, que hace referencia a la extinción de las obligaciones por imposibilidad, y el artículo 1732, que se refiere a los efectos que ella conlleva en la responsabilidad civil (la eximición del deudor). Estas dos normas establecen una serie de requisitos que la imposibilidad de cumplimiento debe reunir para producir esos dos efectos (extinción de la obligación y exoneración del deudor). El primero de ellos pasa por el hecho de que la imposibilidad ha de ser causada por un caso fortuito. El caso fortuito está definido expresamente por el Código Civil y Comercial argentino con los tres elementos con los que la doctrina en general suele reconocerlo: la imprevisibilidad, la inevitabilidad y la exterioridad respecto a la actividad del deudor.

Entonces, la primera pregunta que corresponde formularnos es si el brote de coronavirus, así como las medidas adoptadas como consecuencia de este por las autoridades estatales -como el aislamiento social preventivo y obligatorio-, constituyen realmente un caso fortuito. Poca duda cabe sobre ello en lo que respecta a las limitaciones a las actividades de los ciudadanos derivadas de los decretos del Poder Ejecutivo, que constituyen un clásico hecho del príncipe.

En efecto, al principio del brote de coronavirus a lo largo de Sudamérica, el aislamiento social obligatorio se impuso en la totalidad del territorio nacional argentino. Esto implicaba no solo que los habitantes debían permanecer en sus casas, sino también la prohibición de una larga serie de actividades. Sin embargo, hoy en día esas medidas se han segmentado según las distintas regiones del país; en algunas - como en la ciudad de Buenos Aires y la provincia homónima- continúan fuertes medidas restrictivas, mientras que en otras zonas tales precauciones se han relajado bastante. 
Ahora bien, creemos conveniente precisar que la propia existencia de la pandemia, independientemente de las normas que establecen restricciones a los derechos de las personas, también constituiría un hecho extraordinario, imprevisible e irresistible. En su momento se ha discutido si otras enfermedades, como la peste, la gripe A, el dengue o la chikunguña, podían constituir o no un caso fortuito. La jurisprudencia francesa, por caso, tiene dicho que esas enfermedades no acarrean un verdadero caso fortuito, dado que se trata de males ya conocidos, o bien de dolencias cuya letalidad no era tan significativa.

No obstante, entendemos que esas consideraciones no serían aplicables en el caso del coronavirus, porque su aparición es muy reciente, porque existen todavía grandes interrogantes acerca de su funcionamiento en el mundo científico, porque tiene un extraordinario nivel de contagiosidad y porque, además, presenta un nivel importante de letalidad - por lo menos para ciertos grupos de riesgo-.

Entonces, consideramos que la propia pandemia del coronavirus, independientemente de las restricciones que en consecuencia dispusieron las autoridades, constituye en sí misma un caso fortuito. De hecho, también en Francia, al menos dos tribunales (la Corte de Apelaciones de Colmar y la de Burdeos) han considerado que el riesgo del contagio derivado del COVID-19 que impide a las personas asistir a las audiencias judiciales constituye un caso fortuito.

La importancia de esta conclusión estriba en que podría llevar a justificar la existencia de un casus incluso con anterioridad al dictado de las medidas restrictivas. Por ejemplo, si un viaje programado se cancela semanas antes de que entren en vigor las medidas restrictivas en el territorio nacional, dado que en el país de destino había una circulación significativa del virus; o si quien había alquilado un local para la realización de un evento masivo cancela dicho evento pocos días antes del dictado de aquellas medidas.

Adicionalmente, el Código Civil y Comercial argentino dispone que la imposibilidad de cumplimiento debe ser sobrevenida. Sobre el particular, no cabe duda de que, en la medida en que se trate de contratos celebrados con anterioridad a que sobrevenga la pandemia del coronavirus, estamos ante una imposibilidad sobrevenida.

Asimismo, según la ley, la imposibilidad debe ser objetiva, lo que significa que ha de referirse a la prestación en sí y por sí considerada, y no a situaciones personales o patrimoniales propias del deudor. Es importante señalar que tanto esta característica como la que veremos a continuación tienen una influencia directa en las obligaciones de dar sumas de dinero, ya que este nunca perece. Por esa razón, el deudor no podría escudarse en una imposibilidad sobrevenida para eximirse de la obligación de pagar. Si el deudor no tiene dinero (por ejemplo, porque no puede explotar su negocio debido a las restricciones vigentes), esto implicaría una imposibilidad subjetiva y tampoco sería absoluta, en la medida en que el dinero nunca perece. Lo que sí podría afectarse por la 
situación actual no sería la obligación de pagar en sí misma, sino el lugar de pago; pero esto, a lo sumo, daría lugar a una imposibilidad temporal, durante el tiempo razonable para que las partes pudiesen acordar otro modo de hacerse efectivo el pago (como una transferencia bancaria).

Por otro lado, la característica principal de la imposibilidad tal y como la estructura el Código Civil y Comercial argentino estriba en que ella debe ser absoluta, lo que significa que no ha de poder ser resistida o vencida por las fuerzas humanas. Dicho de otro modo, ni aun con los mayores esfuerzos posibles el deudor - ni este ni ningún otrodebe poder vencer esa imposibilidad.

En nuestro caso, queda claro que el aislamiento social obligatorio y, por lo tanto, la prohibición legal de ciertas actividades implican una imposibilidad absoluta de realizar tales actividades, así como de cumplir prestaciones que las personas deben forzosamente ejecutar fuera de sus domicilios (salvo los casos de las actividades consideradas "esenciales" y expresamente permitidas).

A lo que se suma que en ciertos casos el riesgo de contagio puede generar una imposibilidad moral, es decir, no necesariamente una imposibilidad absoluta desde un punto de vista objetivo. Por ejemplo, podría ser posible que alguien se traslade materialmente para cumplir una determinada actividad. Empero, si se tratase de una actividad o una situación que puede generar un alto nivel de riesgo de contagio, entonces estaríamos ante lo que llamamos una imposibilidad moral. El Código Civil y Comercial argentino prevé esta hipótesis cuando, en el último párrafo de su artículo 1732, dispone que la exigencia de la imposibilidad absoluta ha de apreciarse teniendo en cuenta el ejercicio regular de los derechos y las exigencias de la buena fe. De tal forma, en ciertos casos, cuando el cumplimiento de la prestación sea todavía posible desde el punto de vista material, pero esté reñido con la buena fe, el juez puede de todos modos calificar la existencia de una imposibilidad que exime al deudor.

En otro orden de ideas, que la imposibilidad deba ser absoluta no quiere decir que aquellos casos en los cuales el deudor requiere un esfuerzo extraordinario para cumplir no pueden ser tenidos en cuenta por la ley. Sin embargo, esto no se daría ya bajo el prisma de la imposibilidad, sino sobre la base de la teoría de la imprevisión. Ello supone que, aunque no se llegue al límite de la imposibilidad, el deudor puede pedir un reajuste o eventualmente la resolución del contrato, como consecuencia de que su prestación se volvió excesivamente onerosa por circunstancias sobrevinientes e imprevisible para las partes.

Otra característica que la imposibilidad tiene que reunir consiste en que debe ser definitiva. Si la obligación ya no puede ser cumplida en el futuro, entonces la obligación se extinguiría y no habría ni cumplimiento forzado ni responsabilidad del deudor. En 
cambio, si la imposibilidad es meramente temporaria, la doctrina está de acuerdo con que solo habría una suspensión de la responsabilidad por mora, pero una vez superada la imposibilidad el deudor debe cumplir la obligación.

Nos parece importante señalar esto último debido a que sabemos que en algún momento la pandemia terminará, al igual que las restricciones a las actividades de las personas establecidas normativamente. Entonces, en la medida en que puedan retomarse las actividades y en que se acabe la pandemia, las obligaciones que han quedado suspendidas por imposibilidad transitoria o temporaria podrán ser ejecutadas, siempre y cuando no exista un plazo esencial o la demora no haya frustrado de manera definitiva el interés del acreedor, casos en los cuales estaríamos en el supuesto de una imposibilidad definitiva y no temporaria.

Finalmente, la legislación argentina señala que la imposibilidad, para poder extinguir la obligación y liberar al deudor, no ha de ser imputable al hecho del obligado. Entendemos que, más allá de algún caso en el que una persona se exponga imprudentemente a una situación de contagio - lo que le impediría aducir la enfermedad como un supuesto de imposibilidad-, o bien de quienes ya se encontraban en mora con anterioridad al inicio de la pandemia, dicho requisito también estaría cumplido frente a la imposibilidad causada por la pandemia o por las medidas administrativas o legales que impiden la circulación o la realización de ciertas actividades.

Hasta aquí hemos hablado de los efectos que la imposibilidad tiene en las obligaciones. Ya hemos mencionado que el Código Civil y Comercial argentino regula esta cuestión cuando regla el incumplimiento de las obligaciones en general, mas no cuando se refiere específicamente a los contratos, a diferencia de lo que sí sucede con otros ordenamientos, como por ejemplo el Código Civil y Comercial italiano o el Código Civil francés, que contemplan separadamente los efectos de la imposibilidad para las obligaciones y para los contratos. En Argentina, en cambio, no hay una norma general para los efectos de la imposibilidad en materia de contratos.

Ahora bien, cuando el análisis se traslada al contrato, es decir, a los efectos que la imposibilidad de cumplimiento de una obligación tiene en el marco de un contrato, no es posible extrapolar sin más el sistema previsto para las obligaciones sin considerar el contexto en el que ellas se ubican. Así, en el caso del alquiler de un salón de fiestas, uno podría sostener que para el locador del salón se tornará imposible el cumplimiento de la obligación bajo la coyuntura actual; pero, en cambio, para quien arrendó el salón todavía sería posible pagar, por lo que seguiría obligado a hacerlo. Es evidente que esa no puede ser la solución: en tales casos, la imposibilidad de cumplimiento de una obligación tiene necesariamente que repercutir en la economía general del contrato y, por lo tanto, salvo que se trate de obligaciones accesorias o secundarias, debe también generar la extinción del contrato en su totalidad. Lo anteriormente expuesto no se encuentra mencionado de 
modo expreso en el Código Civil y Comercial argentino - al menos de manera general y para todos los contratos-, pero hay diversos ejemplos en la regulación especial de varios de ellos: el contrato de locación de cosas, el contrato de obra o de servicios, el consorcio de cooperación, el comodato, etcétera.

Además, a la misma solución podría llegarse en Argentina por otra vía: la invocación de la frustración del fin del contrato, prevista en el artículo 1090 del Código Civil y Comercial. Este último establece que la parte perjudicada puede resolver el contrato cuando se frustra definitivamente su finalidad, si ello tiene su causa en una alteración de carácter extraordinario de las circunstancias existentes al tiempo de su celebración, ajena a las partes y que supera el riesgo asumido por la que es afectada. Dicha "finalidad" no es otra que la causa fin del contrato, que el código (artículo 281) reconoce tanto en su versión objetiva (el fin inmediato autorizado por el ordenamiento jurídico que ha sido determinante de la voluntad) como, según los casos, en la subjetiva (los motivos exteriorizados que hayan sido incorporados al acto en forma expresa o tácita, si son esenciales para ambas partes).

Ahora bien, en la medida en que la finalidad objetiva del contrato tiene que ver con el cumplimiento del fin típico del negocio (verbigracia, en la compraventa, el intercambio de cosa por precio), si una de esas prestaciones no puede ya cumplirse, habría una frustración de la causa fin objetiva del contrato, y por esta vía también podría llegarse a la conclusión ya planteada, según la cual la imposibilidad de cumplimiento de una obligación principal del contrato generaría la resolución del acuerdo.

$\mathrm{Si}$, en cambio, se tratara de una imposibilidad temporal, el contrato quedaría suspendido y ninguna de las partes estaría compelida a cumplir sus obligaciones hasta que cesara la imposibilidad temporal. Estimamos que en esta última situación se encuentra hoy en día una buena cantidad de contratos: los de espectáculo público, los referidos a gimnasios y natatorios, los de limpieza o seguridad de locales comerciales y los de construcción inmobiliaria, entre muchos otros, se han suspendido -en principio- de manera temporal, y en algún momento, salvo que en el medio se frustre irreversiblemente el interés del acreedor, podrán continuar siendo ejecutados luego de la pandemia.

Para concluir, cabe hacer hincapié en un tema que se encuentra en debate en la doctrina argentina: la eventual obligación de renegociar los contratos. Sobre el particular, varios juristas han avanzado la idea de que, incluso existiendo imposibilidad de cumplimiento en los términos que hemos mencionado previamente, habría una obligación de las partes de renegociar el contrato para evitar su extinción. Idea que no compartimos.

La renegociación de los contratos se halla prevista por el Código Civil y Comercial argentino en casos sumamente puntuales. Ya mencionamos que, en los casos en que fuese de aplicación la teoría de la imprevisión, esto podría desembocar en una renegociación entre las partes para evitar la readecuación judicial. 
Otro caso en el cual el Código Civil y Comercial argentino expresamente menciona la renegociación del contrato se encuentra establecido en su artículo 1011, que dispone que, en los contratos de larga duración, quien tiene intenciones de rescindir debe dar a la otra parte la posibilidad de renegociar de buena fe. En este caso, la regla de la renegociación se explica por el hecho de que, en los contratos de larga duración, las prestaciones no están fijadas de una vez y para siempre, sino que se van adaptando en función de las circunstancias. Por ejemplo, los contratos de servicios educativos en Argentina han experimentado cambios importantes como consecuencia de la pandemia del coronavirus. No hay clases presenciales, pero las instituciones educativas prestan sus servicios por medio del auxilio informático. Allí tendría sentido una renegociación que permitiera adaptar la cuota que se paga a las exigencias impuestas por las nuevas realidades (disminución de gastos fijos de las escuelas, etcétera).

Ahora bien, en el resto de los contratos, y exceptuando los casos de imprevisión, el código consagra otro sistema. Si hay incumplimiento, el único límite es la imposibilidad. Si hay imposibilidad, hay extinción del contrato, y quien tiene derecho a prevalerse de la extinción no tiene por qué verse obligado a renegociar sobre la base de principios que, si bien son muy atendibles - como la buena fe o la conservación del contrato-, no pueden pulverizar un pilar fundamental del derecho de las obligaciones y los contratos, como es la regla de la fuerza obligatoria. Es muy peligroso sostener que, ante una situación excepcional como la que estamos viviendo, tal principio cede frente a una supuesta obligación de renegociar, porque una vez abierto ese grifo el acreedor ya nunca estará seguro de que, cuando reclama legítimamente la ejecución o - según los casos- la resolución de un contrato, el juez no le dirá que en realidad debía haberlo renegociado. Con ello, se minaría severamente la seguridad jurídica.

Una cuestión distinta sería que el propio legislador estableciese, para este caso excepcional, medidas de emergencia que obliguen a renegociar ciertos contratos, tal y como ocurrió, por ejemplo, en España con los contratos de consumo. Esto último no solo es conveniente, sino que resulta absolutamente necesario, pero sería peligroso suplir la inacción del legislador creando pretorianamente, sobre la base de principios vaporosos, una obligación de renegociar que equivale a decir que los contratos ya no son realmente vinculantes, dado que, incluso si se incumplen o se extinguen, hay que renegociarlos. 